\title{
Uma escola sem partido: dicursividade, currículos e movimentos sociais
}

\section{A school with no political party: discursivity, curriculum and social movements}

\author{
Fabiana Aparecida de Carvalho ${ }^{1}$, Alexandre Luiz Polizel², Eliane Rose Maio ${ }^{3}$
}

\section{Resumo}

\begin{abstract}
Este ensaio objetiva problematizar o movimento Escola Sem Partido (ESP) e seus atravessamentos, como gerador de efeitos, junto aos currículos escolares. Como movimento social, o ESP atua nos domínios da escola e do currículo implementando uma pedagogia cultural e estratégias biopolíticas que excluem as diferenças nesses contextos. Trata-se de uma estratégia de vigilância, coerção e proibição que nega certas discussões e posicionamentos na escola. O movimento tem ganhado espaço em projetos de leis que intensificam essa vigilância por sobre os educadores e alunos. Destacamos alguns enunciados discursivos do movimento que discutem a sua insurgência em meio às políticas nacionais; como ele se caracteriza em um dispositivo constitutivo e gerador de efeitos por sobre as identidades escolares; como cria um fluxo discursivo que poderá atravessar modos de ver e pensar a educação, a docência, os alunos, o posicionamento dos pais para com a escola e as identidades dentro desse território.
\end{abstract}

Palavras-chaves: Escola sem partido. Currículo. Discursos. Biopolítica. Movimento social.

\begin{abstract}
This essay aims to discuss the movement School with no Political Party (ESP) and its crossings, as effect generator, along with the school curriculum. As a social movement, ESP operates in the school curriculum areas and implementing a cultural pedagogy and biopolitical strategies that exclude differences in these contexts. This is a surveillance strategy, coercion and prohibition that deny certain discussions and positions at school. The movement has gained space in law projects that enhance this surveillance on educators and students. We highlight some discursive statements of the movement discussing their insurgency among the national policies; as it is characterized in a constituent device and effects generator for on school identities; it creates a discursive flow that can pass through ways of seeing and thinking about education, teaching, students, parental placement to the school and identities within that territory.
\end{abstract}

Keywords: School without political party. Curriculum. Discourses. Biopolitics. Social movement.

\footnotetext{
${ }^{1}$ Doutoranda no Programa de Pós-graduação em Educação para a Ciência e a Matemática. Professora Assistente do Departamento de Biologia da Universidade Estadual de Maringá - UEM.

${ }^{2}$ Graduando em Ciências Biológicas pela Universidade Estadual de Maringá. E-mail: alexandre_polizel@hotmail.com.

${ }^{3}$ Professora Dra. Adjunta do Departamento de Teoria e Pratica da Educação da Universidade Estadual de Maringá.
} 


\section{Com o Efeito de Problematizar o Presente - um Caso de Fiscalização e Controle na Escola}

O ano de 1925 presenciou um dos arbitramentos mais emblemáticos e contundentes envolvendo escola e questões filosóficas, religiosas e políticas a mobilizar o poder judiciário e a opinião pública. $\mathrm{O}$ chamado "Julgamento do Macaco" (Monkey Trial) foi uma ação movida no Estado norte-americano do Tennesse contra o professor de biologia John Thomas Scopes, da cidade de Dayton, acusado de ensinar, dentro de colégios públicos, a teoria da evolução e as bases biológicas das dinâmicas adaptativas das populações e dos espécimes de diferentes seres vivos. O episódio, que teve proporções internacionais e transmissão via rádio a diversos países, sobrevive nos anais da história por sua polêmica e ironia, chegando-nos à atualidade após ter sido celebrizado e encorpado na narrativa fílmica "O vento será sua herança", tanto na versão de 1960 dirigida por Stanley Kramer e estrelada por Spencer Tracy e Genne Kelly, quanto no remake de 1999, que trazia Jack Lemon protagonizando o advogado de defesa do acusado. A moral do filme, numa espécie de crítica ao episódio real, é uma referência ao versículo 29 , do Provérbio 11, do livro bíblico Provérbios, que vaticina os insensatos como escravos dos sábios e os criadores de desordem à casa divina e à família destinados a ter o vento e a tempestade como heranças.

No caso em questão, o referido professor de Biologia, por ter feito um contraponto político e científico em sua prática docente, fora preso por infringir a Lei Butler Act, que impunha aos funcionários públicos um código de posturas e de condutas cuja base ideológica se amparava na moralidade e na não contestação dos pontos de vistas e afirmações religiosas advindas da família e da igreja.

A cidade de Dayton posicionou-se contra o acusado e seu advogado, quando se viu questionada em suas convicções criacionistas e judaico-cristãs, organizando grandes campanhas contra o ensino de Darwin nas escolas, especialmente em relação à tese da ancestralidade comum para homens e para símios quando, cientificamente, se considera a ordem primata e seus parentescos biológicos. As pessoas que se opuseram a essas concepções e se alinharam ao pensamento darwinista foram categoricamente chamados de pecadores e ateus e, numa verdadeira caça às bruxas, sofreram sanções em suas paróquias e pequenos grupos comunitários.

A campanha empreendida na pequena cidade foi tão bem sucedida que proporcionou a extensão da Lei, além do Tennesse, em Oklahoma, Florida, Mississipi, Carolina do Norte Kentuchy e Arkansas, territórios que conformavam o cinturão bíblico americano e locais onde a religião perfazia grande peso cultural. $\mathrm{O}$ dispositivo legal "proibia o ensino, nas escolas públicas financiadas pelo Estado, de qualquer teoria que negue a história da Criação Divina do homem, tal como ensinada na Bíblia, a favor da teoria de que o homem descende de uma ordem inferior de animais" (CALADO, 2014). Ele seguiu a impor censura e cerceamento a professores de escolas e universidades que contestaram o relato bíblico sobre a origem das espécies, como também a impedir que na disciplina de biologia houvesse qualquer menção, naquele momento, à teoria da evolução.

Durante o julgamento de Scopes, o mote da defesa amparou-se no direito de liberdade de expressão, das diferenças, do livre pensar e do acesso ao conhecimento científico, trazendo como contra argumento às convicções religiosas a Revolução de Copérnico, a Evolução Sexual e o próprio Darwinismo enquanto teses defendidas pela ciência. A acusação da promotoria contra o réu pautou-se, contudo, nas explicações garantidas pela Bíblia, pela igreja e pela crença hegemônica da população, refutando qualquer argumento científico junto ao júri e durante a seqüência das conjecturas julgadas.

Ao final de 11 dias e com a vitória da acusação, o professor, sendo impedido de depor no próprio julgamento e de expor sua defesa ou suas explicações

4 As aproximações com o "Julgamento do Macaco" estão moldadas pela leitura/análise da versão original do filme em preto e branco, dirigida por Stanley Kramer e lançada em 1960. Essa versão é facilmente encontrada em cópias DVDs e arquivos digitais disponíveis em livrarias e na internet. 
sobre seu desdobramento em sala de aula, foi condenado a pagar uma multa irrisória de 100 dólares ao Estado e impedido temporariamente de lecionar nas escolas locais. A Lei Butler Act somente foi revogada em 1967 após 42 anos de o caso ter entrado em juízo e sua anulação abriu precedentes para uma emenda constitucional que proíbe, a qualquer Estado americano, a imposição de regras educacionais baseadas em princípios ou dogmas religiosos.

Mais de 90 anos se passaram deste emblemático caso que ilustra a invasão do domínio público da escola por crenças de foro privado e particular e a aplicação de uma lei para "vigiar e punir" (FOUCAULT, 2014). Embora nossa contextualização possa parecer, durante o intervalo desta escrita, uma dicotomia de pensamentos engendrada pelo antagonismo de explicações científicas versus explicações religiosas para a origem do mundo, o episódio do "Julgamento do Macaco" está aqui posto, como mote inicial do ensaio, para discutirmos como a interferência de grupos políticos, religiosos ou hegemônicos criam efeitos na constituição dos currículos e das pessoas quando se perpetra a imposição de opiniões e o cerceamento das diferentes expressões dos saberes na escola.

O episódio ocorrido nos Estados Unidos não é uma simples digressão ao passado e, tão pouco, uma elucidação da oposição ciência e religião. Tratase, conforme apontou Michel Foucault (1984), de arrastá-lo para pensar, ver e refletir o presente que vivemos diferentemente do já condicionado e, mais propositadamente, de defender a liberdade e a multiplicidade de outros pensamentos e identidades. Tentamos, ao nos aportar numa historiografia recente, discutir como certos discursos puderam acontecer e se sustentaram na conjectura atual do país não colocando o foco na infração de uma lei que pode, hoje, pode nos parecer absurda, nem na oposição de criacionismo e evolucionismo, mas perguntando, em conjunto com as pessoas leitoras, como determinadas correlações de força e contingências podem perfazer efeitos constitutivos e determinar currículos escolares, incidindo direta ou indiretamente na liberdade de pensamento, na livre circulação de ideias, nas explicações e contextualizações de saberes, nos princípios laicos e de coletividade e na sustentação dos direitos garantidos a toda diferença presente na escola.

Este movimento de pensar o pensamento e as contingências está próximo do problematizar um conjunto de regras que irão conformar o surgimento ou o desaparecimento de enunciados e de discursos dizíveis em nossas culturas e sociedades (FOUCAULT, 1987). Neste sentido, importamos em tomar algumas formações discursivas e seus efeitos dentro da materialidade, contingência, temporalidade e atuações que irão conformar o chamado Movimento Escola Sem Partido (ESP) e de suas proposições específicas que estão inscritas e reproduzidas em certas instâncias e práticas culturais.

O ESP insurgiu no país, ainda que inexpressivamente, em 2004, como iniciativa conjunta de estudantes e familiares empenhados em promover mudanças na estrutura jurídica do direito à educação e de regularizar a liberdade de cátedra ao ditar regras para a livre expressão nas escolas brasileiras, sendo motivado por três objetivos: "a descontaminação e desmonopolização política e ideológica das escolas; o respeito à integridade intelectual e moral dos estudantes; e o respeito ao direito os pais de dar aos seus filhos uma educação moral que esteja de acordo com suas convicções" (CARA, 20116, p. 4). Seu mentor, fundador e proponente, o advogado paulista Miguel Nagib, corrobora com uma rede difusa composta por corporações particulares de educação e de sistemas de ensino, famílias, partidos políticos ligados a determinadas empresas, igrejas e convicções doutrinárias cuja principal finalidade, no âmbito escolar, seria a de delimitar o papel do professor e da escola ao nível da instrução técnica, ou seja, como agentes responsáveis pelo ensino e não pela educação de seus alunos.

De acordo com o site oficial do ESP, é necessário "descontaminar" a escola de posições políticoideológicas cujos pretextos seriam transmitir uma visão crítica da realidade através da doutrinação dos estudantes. Esta ideia se inspirou na Organização Não 
Governamental norte-americana "No Indoctrination", que fomentou um canal de contato com pais e estudantes que denunciavam casos em que teriam sido vítimas da ideologia partidária na escola. Além disso, o movimento difama ou se posiciona contrário aos ideais da Pedagogia do Oprimido de Paulo Freite, da Geografia Crítica de Milton Santos, das correntes vinculadas à Teologia da Libertação, especialmente as alinhadas ao pensamento de Frei Beto, e aloca todas essas posições teóricas como herdeiras do Marxismo que seria, segundo o movimento, o pensamento responsável pela doutrinação social na escola.

De acordo com Salomão Ximenes (2016), embora recente em termos de história educacional do país, o movimento deus sinais de forte ascensão a partir de três vetos governamentais cedidos em função das pressões políticas: a) a retirada de ações referentes à promoção de direitos sexuais, reprodutivos, laicos, de livre expressão e de reparação contra os crimes da ditadura do Programa Nacional de Direitos Humanos (PNDH) - realizada pelo então Presidente Lula em 2009; b) a proibição no Governo Dilma, em 2011, ao Programa Educacional Brasil Sem Homofobia no ensino fundamental e médio; e, c) a ampla campanha contra a diversidade sexual e cultural nos planos decenais de educação a partir de 2014 que inabilitou a educação para os gêneros e para os pertencimentos sociais como metas educacionais a serem cumpridas no país como um todo.

Vale destacar que, ainda no ano de 2013, o movimento ganhou forças a partir das movimentações dos setores sociais mais conservadores representados por alguns partidos políticos e por organizações como o Movimento Vem Pra Rua e o Movimento Brasil Livre (MBL), que defendem o neoliberalismo e estão intrinsicamente ligados à economia de mercado. Desde então, o ESP dissemina um discurso de neutralidade a ser seguido e desempenhado por toda a comunidade escolar e, mais especificamente, por professores. Apregoa a não sobreposição e a não contestação dos princípios educacionais adquiridos na educação familiar e se posiciona veementemente contra ao ensino de temas contundentes ou de caráter socialista.

O movimento constela uma investida biopolítica direcionada às escolas e imprime uma herança circunstanciada a jogos de saber e poder que denigre educadores na liberdade de ensinar, na mobilidade de conteúdos e na flexibilização curricular já amparadas pelas leis e diretrizes educacionais do país. Por biopolítica podemos compreender certo número de procedimentos de controle e disciplina que visam o governamento das pessoas que compõem uma dada população ou de grupos subalternizados por tecnologias de poder que asseguram uma melhor gestão da força do trabalho e da produtividade econômica, assim, ela opera tanto pelo anato-poder, ou seja, pela gestão dos corpos individuais, como pelos biopoderes compreendidos pela gestão que se aplica ao corpus social e à vida a ser controlada (REVEL, 2005; FOUCAULT, 1995).

Diante do exposto, nossa proposição está em discutir o ESP e sua influência direta ou indireta nos debates educacionais, tomando alguns aportes teóricos pós-críticos ${ }^{5}$ que se atentam à constituição de discursos e enunciados, posicionamentos teóricos que questionam a base autoritária e anti-constituicional do movimento, autores e autoras do campo de análise do currículo e demais que analisam manifestações ideológicas para perguntarmos: a) como insurge o ESP em meio às políticas nacionais; b) como ele se caracteriza em um dispositivo constitutivo e gerador de efeitos por sobre as identidades escolares; e, c) como ele cria um fluxo discursivo que poderá atravessar modos de ver e pensar a educação, a docência, os alunos, o posicionamento dos pais para com a escola e as identidades dentro desse território.

\footnotetext{
5 Para efeito de compreensão, entendemos por teorias pós-críticas um conjunto de teorizações que questionam os limites das teorias críticas e marxistas ao trazer, para o cerne das discussões, as problematizações das relações de poder na educação, da construção das identidades nos modos de governamentabilidade e subjetivação, dos conhecimentos, verdades e discursos que entram na composição da produção de saberes na educação, da construção de subjetividades e contra-poderes, da centralidade cultural dessas questões e, principalmente, dos limites impostos pela linguagem e de sua própria posição como instituidora de modos de ser e estar. Neste ensaio são utilizados aportes Foucaultianos tomados por teorizações pós-críticas, principalmente por acreditarmos que eles permitem a compreensão dos efeitos de poder, controle e disciplina no campo educacional.
} 


\section{Aproximando-se da Genealogia: o Currículo como Efeito e Produtor de Identidades}

Antes de adentrarmos especificamente nas delineações do ESP, gostaríamos de apontar a noção que embasa nosso plano de ideias sobre o que vem a ser um currículo. Diferentemente da perspectiva teórica que o toma como documentos articuladores de grades, conteúdos, temporalidades, aspectos formais da educação e de disciplinas a serem distribuídas ao longo da escolarização, amparamo-nos na concepção de que os currículos são artefatos culturais que não apresentam significados fixos; eles são, portanto, negociados, moldados e tracionados de acordo com o contexto cultural em que estão inseridos.

Algumas teorias pós-críticas ampliam o conceito de currículo tomando-o como artefato produzido discursivamente dentro de relações sociais e dentro de relações de saber e poder que o constituem epistemologicamente. Eles analisam, organizam, instituem e legitimam os saberes escolhidos como formativos e muitos discursos e perfazem aquilo que estará circunscrito em outros documentos e proposições escolares. Neste sentido, algumas culturas, saberes, negociações, debates, entendimentos e posições podem estar presentes ou negados no currículo em função da também presença ou apagamento de outras proposições e culturas (SANTOMÉ, 2013).

O que entra nesses documentos está em constante território de contestação, pois nem sempre os saberes oficiais dão conta de atender e representar outros discursos e identificações, assim, os grupos minoritários ou marginalizados socialmente, por exemplo, podem estar estereotipados ou invisibilizados nos currículos para que se neutralizem suas posições e para que a escola se adapte aos discursos hegemônicos. A resistência a esse repertório oficializado e colonizado conclama a abertura para a inserção de diálogos, saberes e significados que tragam para o campo das discussões as alteridades, a pluralidade, o multiculturalismo e as diferenças (POLIZEL; CARVALHO, 2016; SILVA, 2015; SANTOMÉ, 2013; GOODSON, 2008).
Estas trações são para se deslocar continuamente os currículos (seja ele de caráter oficial, interacional, oculto ou hibridizado com questões culturais) não se dão somente ao nível dos órgãos oficiais e do Estado; ao contrário, elas também são derivadas de fluxos e de movimentos sociais organizados que irão, dentro de correlações de força, abrir espaços para as múltiplas identidades se narrarem, manifestarem seus direitos, suas consciências e exigirem suas visibilidades. Dentro dessas relações, o currículo pode ser entendido como a um espaço de disputa e

[...] um dos locais privilegiados onde se entrecruzam saber e poder, representação e domínio, discurso e regulação. É também no currículo que se condensam relações de poder que são cruciais para o processo de formação de subjetividades sociais. Em suma, currículo, poder e identidades sociais estão mutuamente implicados. O currículo corporifica relações sociais (SILVA, 1996, p. 23).

Muitas dessas relações e movimentos que negociam a presença de certas identidades nas cenas culturais, a exemplo, a negro e a LGBTTQIA ${ }^{6}$, têm sido responsáveis pela inclusão de suas pautas nas escolas e pelo reconhecimento das diversidades étnicas, regionais e sexuais e pela valorização das identidades e diferenças nos currículos. Esses mesmos grupos têm enfrentado respostas ou ataques de setores conservadores que buscam silenciá-los, criando mordaças que tiram o direito de fala dos diferentes (ARROYO, 2015) e esvaziam as múltiplas vozes dos espaços educacionais.

Por outro lado, ao se considerar o currículo como prática, onde se encontram questões sociais enunciáveis, visíveis, discursivas e não discursivas difusas junto ao emprego de táticas de ensino e de aprendizagem, podemos tomá-lo como um dispositivo (FOUCAULT, 1995, 1988) que tem como função estratégica a constituição das pessoas e certa vontade de saber para governar e para subjetivar, debruçandose na disciplinarização os corpos e na regulamentação da população naquilo que ela pode ou não fazer

\footnotetext{
${ }^{6}$ Sigla que designa pessoas lésbicas, gays, bissexuais, trangêneras, transexuais, queers, intersexuais e assexuadas.
} 
criando e perfazendo, dentro das escolas, biopolíticas que vão regimentar a vida social deste espaço.

As expansões dos significados de currículo para pautá-los como dispositivos e geradores de efeitos nas pessoas que perpassam as escolas ajuda-nos a compreender a insurgência do ESP como uma pedagogia cultural e toda a sua preocupação em regular, regimentar, coordenar, controlar e dispor sobre as táticas de ensino, as posturas teóricas, os encaminhamentos e respaldos metodológicos e sobre a conformação de pessoas para dentro de um projeto de sociedade que eleva o regime privado ao denegrir a coletividade e a dinâmica pública das instâncias sociais e ao decalcar na escola a perspectiva da neutralidade ideológica.

Apesar do incessante destaque à neutralidade nos processos do ensinar e do aprender, o ESP desconsidera, entre outros aspectos, justamente as lutas e os conflitos que proporcionam a existência de documentos curriculares. Autores como Henry Giroux (1997) e Michael Apple (1989) já nos alertaram que as relações entre currículo e poder refletem as tensões e alianças que determinam quem legitima e escolhe o conhecimento a ser transmitido e quais as questões sociais irão compor, junto a outras posições políticas, sociais e econômicas, os saberes escolares. Não há currículo neutro e nenhuma concepção de sociedade, educação e ensino está livre de traços, fundamentos ou bases ideológicas que são apropriadas pelo "Estado para reproduzir e regularizar hierarquias e desigualdades de raça, de classe e de gênero" (GIROUX, 2003, p. 85).

Ao trazer essas contradições e situá-las em nossa atualidade, presenciamos um território de contrastes e disputas que se tracionam para comportar aquilo que estará na escola. No mesmo tempo em que temos diretrizes educacionais que complementam a Lei de Diretrizes e Bases da Educação (LDB 9.344/96) (BRASIL, 1996), a atuação de Secretarias especiais vinculadas ao Ministério da Educação (MEC) e demais ministérios da união, no que tange à garantia de direitos para as minorias sociais e a disseminação de políticas públicas educacionais numa perspectiva de abrir espaços e diálogos junto às diferenças (RODRIGUES; ABRAMOWICZ, 2013), temos também a ascensão de muitos movimentos sociais de caráter conservador e fundamentalista que se ocupam das pautas políticas e tentam impedir o acesso dos grupos minoritários à vida pública. Movimentos como: Cristãos contra a Ideologia de Gênero, Família na escola, Movimento Brasil Livre e o próprio ESP são exemplos de uma retomada de poder por setores sociais que se sentiram legitimados, ocupando também os poderes legislativo e judiciário do país, para impor e disseminar suas convicções fundadoras e seus projetos educativos.

Como dispositivos de controle, esses movimentos irão perfazer documentos escolares e participar da construção discursiva da sociedade, da escola e de pessoas ao inventarem suas metas educacionais e produzirem efeitos formativos. Conforme crescem em volume e participação nas decisões sociais, vão também aliciando demais agrupamentos que contrapõem argumentos religiosos para descaracterizar os científicos, criando, numa tautológica repetição de regras e proposições com vieses fascistas, parcerias políticas que resultam nos apagamentos das diferenças nos currículos e práticas escolares. Um exemplo contextualizado dessa operação pode ser delineado pela votação dos Planos de Educação Federal no ano de 2014 e Planos de Educação Estaduais e Municipais no período subseqüente à aprovação do documento nacional.

Os Planos de Educação são importantes documentos educacionais alinhados com proposições internacionais para a melhoria da educação, o combate do analfabetismo e para a criação de demandas e políticas públicas para a área. No cenário brasileiro, a cada 10 anos um Plano entre em vigência contendo objetivos a serem atingidos e metas a serem superadas. A discussão recente em relação aos Planos decorreu da redação do Artigo 2o. do Projeto de Lei original.

Embora preze pela igualdade de direitos e deveres educacionais para todas/os cidadãs/ ãos, a aprovação do PNE foi condicionada (sucumbindo à pressão de políticos que compõem a bancada religiosa no Senado e na Câmara dos Deputados) à retirada de conceitos, terminologias e definições categorizadas como pertencentes a uma suposta ideologia de gênero. Nesses termos, foi drasticamente alterada a redação do Projeto e diretrizes do Plano determinadas pelo Artigo 2o. O Inciso III, que originalmente propunha 'a superação 
das desigualdades educacionais, com ênfase na promoção da igualdade racial, regional, de gênero e de orientação sexual' [...], passou, após emenda sugerida pelo Senado e aprovação do Executivo, a versar sobre: 'a superação das desigualdades educacionais, com ênfase na promoção da cidadania e na erradicação de todas as formas de discriminação' (CARVALHO et al., 2015, p. 102).

$\mathrm{Na}$ esteira dessa modificação, os demais planos das unidades da federação suprimiram os itens que tocam na questão de gênero, etnia/raça, regionalidades e diversidade, reduzindo-os à palavra discriminação e gerando o efeito de um sucinto apagamento que reduz as diferenças e suas peculiaridades a um termo generalizado. Essa medida, além de retirar da cena pública minorias como LGBTTQIA, negros, quilombolas e mulheres, abre precedentes para a livre interpretação das metas a serem atingidas e sua vinculação com a cultura dominante que determinará os investimentos necessários para a conformação de um tipo específico de sociedade.

Apesarde a polêmica terestado mais situada em relação à censura acerca da perspectiva de construção social dos gêneros e das diferenças nos documentos votados, e, num primeiro momento não traçarmos vínculos desse processo com o ESP, é justamente na perscrutação dos gêneros e das sexualidades da população que se estreitam os laços persecutórios do movimento e o poder de controle e de disciplina para que o mesmo ganhe forças e mantenha práticas individuais e grupais sob controle social com o intuito de aumentar o campo de atuação biopolítico nas escolas e nos currículos. A estratégia utilizada não é apenas a de invisibilizar as vozes e atuações dos outros, mas, sim, a de proibir que se fale ou que se componha, nos territórios do ensinar e do aprender, a figura deste outro, ou, ainda, de coibir os constructos teóricos e os saberes que vão legitimar identidades diferenciadas e os conhecimentos não hegemônicos. É nessa correlação de força que o ESP também se converte em um dispositivo pedagógico criando um conjunto de enunciados dispersos em proposições que: a) instauram-se na sua origem; b) defendem a neutralidade; c) impedem a participação pública de estudantes nas tomadas de decisões escolares e nas questões sócio-políticas; d) conclamam a interferência direta da família parental na instituição; e e) promovem, categoricamente, uma desconstrução de educadores e professores referenciada pela demonização do ofício de ensinar.

Deslocamos esses discursos para nossa análise com o interesse de problematizá-los e o ESP numa perspectiva que se aproxima de um caminho genealógico - que pergunta sobre as condições acontecimentais para o surgimento de discurso num esforço de desassujeitar os saberes, isto, é, que percorre uma ontologia de nós e de nossas relações com as verdades, os discursos que nos constroem como sujeitos e com nosso caminho de constituição ética (REVEL, 2005; FOUCAULT, 1988), e da micro-análise da filosofia e prática do movimento, indagando e chacoalhando suas evidências no sentido de apontar como as bases do movimento, através da evidenciação dos discursos por ele disseminados, estão sendo instituídas e sustentadas como efeitos e não causa de um a possível reorganização curricular, escolar e docente. Esta é também uma tentativa de desestabilizar, junto aos leitores e demais interessados, as crenças, as concepções e os efeitos de verdades hegemônicas que se enraízam na medida em que o movimento ganha corpo na sociedade, para tanto, os quatro pontos de análise apresentados são retirados dos pressupostos do ESP através da arguição e da leitura crítica de sua fundamentação descrita em seu site disponibilizado na internet (ESCOLA..., 2016).

\section{ESP: Efeitos de Origem}

Quando se pensam em proposições para a educação no país logo se pensam em reformas de suas bases operadas pelo Estado e por instâncias que se articulam na mobilização política, de recursos financeiros e capital humano para sustentar as mudanças propostas. As escolas acabam por refletir os impactos da sociedade quanto às ordens políticas, econômicas e culturais e, a cada período governamental ou contexto social, elas se ordenam junto à emissão de normativas, regulamentos e deliberações. Logo, a influência de movimentos sociais progressistas ou conservadores nos currículos não pode ser lida como a uma novidade. 
Embora o ESP ainda não tenha se configurado como Lei oficial da Nação, ele tem influenciado categoricamente a elaboração de projetos e dispositivos que tramitam em diversos Estados brasileiros e recebem apoio de organismos, partidos ou mesmo de corporações privadas que criam campos de interesses frente a assuntos estratégicos e mobilizadores de opiniões públicas nas demandas sociais, políticas e econômicas. Os primeiros Projetos de Lei, primeiramente em nível estadual, vieram no ano de 2014 e foram construídos em articulações com o Deputado Estadual Flávio Bolsonaro, que organizou a minuta do Projeto No. 2.974, apresentado em 13 de maio do mesmo ano na Assembléia Estadual do Rio de Janeiro. O mesmo, contudo, ainda aguarda a análise e julgamento desta casa (RIO DE JANEIRO, 2014). Em termos históricos, O ESP se insere num momento de grande complexidade simbólica e política para o Brasil, pois se situa entre as manifestações de junho de 2013 e os episódios de votação dos Planos de Educação um ano depois.

Para Silva et al. (2014), os movimentos de rua que antecederam as eleições se caracterizaram pela recusa das formas partidárias de participação e organização dos movimentos sociais, mas, também, pela presença de grupos conservadores e de extrema-direita que se sentiram legitimados a expor e a impor ao público suas convicções segregadoras, autoritárias e mercadológicas. Ao disseminar suas convicções através da proposição de projetos de lei junto a Câmaras de Vereadores, Assembleias Legislativas e no Congresso, o ESP articulas com as convicções e bases representadas por setores de direita e de centro, mas, também, se articula com bases ideológicas fascistas e contrárias ao avanço dos direitos das minorias sociais. De acordo com Rodrigo Ratier, são desse perfil a maioria dos 19 deputados federais, estaduais ou vereadores que propõem projetos de lei sobre o ESP. O Partido Social Cristão (PSC), a maior sigla da bancada evangélica, é o primeiro em número de proposições, seguido pelo Partido do Movimento Democrático Brasileiro (PMDB) e do Partido da Social Democracia Brasileira (PSDB) (RATIER, 2016).

Este é um dos fatores que, em conjunto com as políticas neoliberais, irá fortalecer as bancadas representantes de igrejas, do agronegócio e dos favoráveis ao armamento da população (apelidadas pejorativamente de "Bala, Boi e Bíblia"). Dentro da Câmara e do Senado Federal e junto aos fóruns estaduais e municipais, elas formaram pressões contrárias à inserção dos termos gênero e diversidade nos referidos Planos de Educação votados a partir de 2014 e, sob a égide judaico-cristã, conclamaram a evocação do direito a "Deus, à Família e à Propriedade" para resgatar a moralidade no país e para se exterminar os comunistas doutrinadores de crianças e jovens; vale lembrar que: "11 dos 19 proponentes de projetos inspirados pelo ESP são ligados a alguma igreja" (RATIER, 2016, p. 35) e que a defesa da moral, da família e dos costumes são promessas de campanha e projetos políticos desses representantes legisladores.

Criticando a situação apontada, Lionço (2015, p. 13-14) postula ser esta uma "estratégia de tomada de poder de extrema direita que se reveste da autoridade religiosa para justificar a inflexibilidade de suas posições no processo de regulação e políticas públicas". A laicidade, um dispositivo político que organiza as instituições estatais, inclusive a escola, foi ferida nesse conjunto de ações e abriu fenestra para que o espaço privado das crenças e dogmas invadisse e encolhesse o espaço público da coletividade e dos direitos.

As ramificações da rede discursiva que se apoiam no conservadorismo político e na afirmação de que as preocupações de raça, de gênero e de orientação sexual sabotam as tradições da cultura ocidental (GIROUX, 2003) não impedem que estas discussões aconteçam e que as leis estejam vinculadas a uma hierarquia de leis de direito civis articuladas em complementariedade e suplementariedade legislativa. Entretanto, o ESP ignora as hierarquias e a constitucionalidade dos direitos adquiridos e amparados nas políticas públicas, qualificandose como uma ação que deve abranger o maior número de unidades para controlar e regulamentar a população escolar. Nagib disponibiliza no site do ESP tanto o Ante Projeto de Lei Federal, que inclui na LDB/1996 o Programa Escola sem Partido, quanto minutas de Lei, que visam garantir a afixação 
de cartazes nas salas de aula das instituições de educação básica pertencentes ao sistema municipal e estadual de ensino.

O Projeto de Lei No. 867/2015 (BRASIL, 2015) foi o primeiro projeto do $\mathrm{ESP}^{7}$ proposto em nível nacional pelo Deputado Izaldi Lucas Ferreira, representante do PSDB-DF, e pressupõe a alteração da LDB/1996 e o combate à ideologia de gênero (BRASIL, 2015), tendo já sido aprovado pela Comissão Permanente da Câmara dos Deputados. No Senado ele é encaminhado pelas mãos Senador Magno Malta (PR-ES), como o Projeto de Lei No. 193/2016 (BRASIL, 2016c). Neste cenário, os projetos se multiplicaram e estão tramitando em 10 Estados da Federação. Os aprovados em Alagoas e no Espírito Santo foram encaminhados ao Supremo Tribunal de Justiça para julgamento por inconstitucionalidade. Dois municípios já aprovaram o ESP (Santa Cruz de Monte Castelo-PR e Picuí-PB). O mapa desenvolvido pela organização Educação e
Participação, representado na Figura I, evidencia o avanço do ESP pelo país.

Vale ressaltar que as minutas se amparam em quatro cânones: a) a neutralidade política, ideológica e religiosa do Estado a fim de permitir a liberdade de crença ao alunado; b) que pais ou tutores têm o direito de assegurar a formação religiosa e moral de seus filhos de acordo com suas próprias conviç̧ões; c) o reconhecimento de que os estudantes são a parte mais fraca na relação de ensino e de aprendizado; e, d) que professores são doutrinadores ou um mal a ser combatido na garantia dessa neutralidade. Esses discursos enviesados e descaracterizados de muitos contextos sociais, teorias educacionais e regimes de leis quando não evidenciados diretamente na redação dos projetos, ficam destacados na dispersão discursiva e na reprodução compulsória de representações e de artefatos culturais difundidos nas páginas de seus idealizadores e/ou apoiadores.

Figura 1 - Mapa elencando os Projetos de Lei do ESP em Municípios e/ou Estados

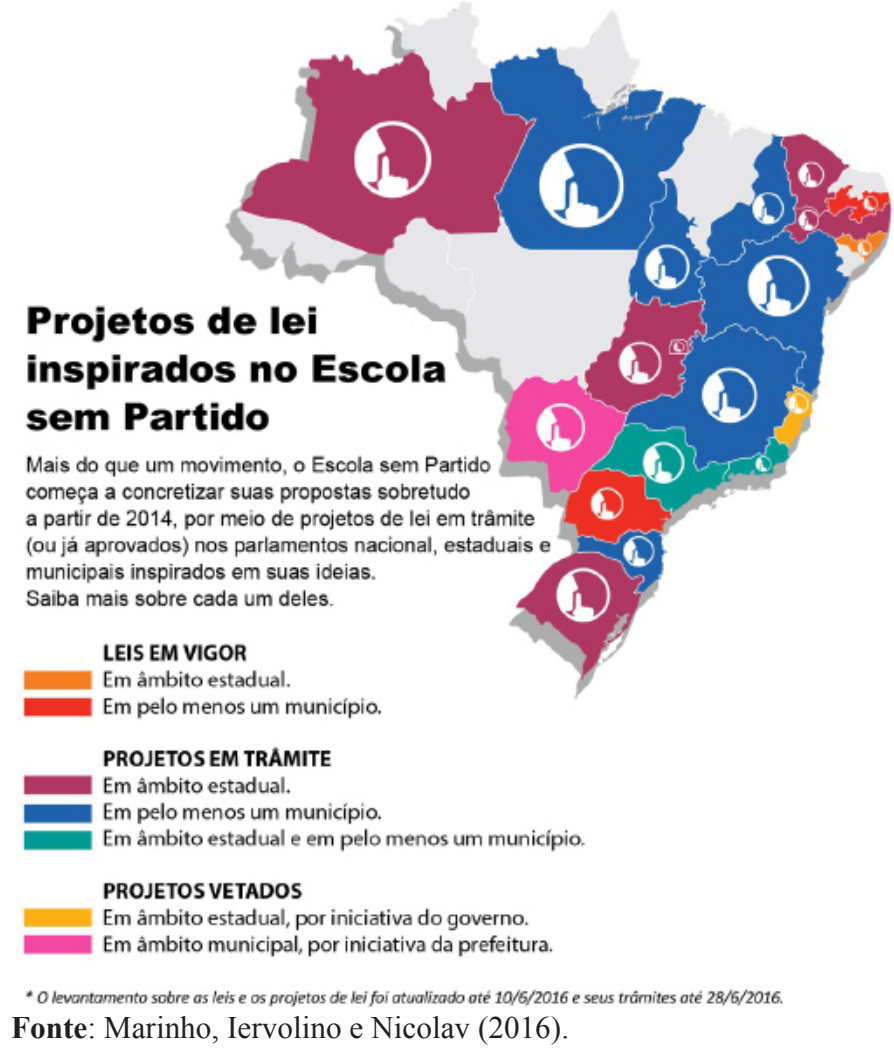

\footnotetext{
7 No nível federal aos projetos em tramitação são: PL 7180, PL 7181, PL 867, PL 1859 e O PL 1411 - este último tipifica a doutrinação como assédio ideológico.
} 
Dispersando os elementos derivativos do discurso do ESP podemos apontar um alerta para elucidar que ele, na prática, propõe uma educação descolada de criticidade e que sustenta o status quo. Questões contundentes como gênero, política, etnia, violência, sistemas econômicos, exploração de classes e subalternização de pessoas deveriam ser proibidos em sala de aula. A escola se encarregaria apenas da formação técnica e conteudista dos estudantes num processo de repetição sistemática dos conhecimentos relativos a cada área ou disciplina. Caberia exclusivamente à família a emissão de opinião ou o respaldo crítico sobre essas questões. Sob uma aparente isenção ideológica e uma fluidez em garantir a escola livre de dogmas partidários, o ESP é uma investida autoritária, pois promove

Indistinção entre o público e o privado, incapacidade para tolerar o princípio formal e abstrato da igualdade perante a lei, combate da classe dominante às ideias gerais contidas na Declaração dos Diretos do Homem [...] e na Declaração dos Direitos Humanos (de 1948), repressão às formas de luta e de organização sociais e populares, discriminação étnica, sexual e de classe (CHAUÍ, 2014, p. 257).

Segundo esses argumentos, os projetos derivados do ESP poderiam ser enquadrados como inconstitucionais. No âmbito da tramitação democrática são demandas de iniciativa isolada e privada de representantes da Câmara e do Senado, o que não condiz com a abertura ao diálogo e à discussão com a sociedade civil, com professores, Secretarias de Educação, pesquisadores e outros movimentos sociais que divergem da proposta apresentada e compõem núcleos de resistência e defesa à escola plural (PINHEIRO NETO, 2016). Embora a efetuação no Legislativo ainda não tenha se concretizado, vale ressaltar, uma vez mais, que o ESP é uma formação discursiva com enunciados difusos que já estão produzindo efeitos e conformando sujeitos, professores e alunos como objetos e alvos de suas falas.

\section{A Defesa da Neutralidade - Seria a Educação Assim?}

Um dos apelos do ESP é a reivindicação de uma educação com neutralidade política, ideológica e religiosa que permita que a liberdade de crença dos alunos seja manifesta no espaço escolar. Dentro dos pressupostos do movimento, é desejável que as escolas formem para a cidadania desde que a escola ofereça diferentes versões de um fato ou contraposições teóricas a uma explicação ou teoria. De acordo com sua argumentação, o principal inimigo deste caráter neutro são organizações partidárias, especialmente as consideradas de esquerda, que se intrometem nos conteúdos escolares por meio das condutas docentes que distorcem a missão de ensinar e aprender e que impõem a doutrinação como o combustível que alimenta a presença de facções e regimes autoritários.

Segundo Pinheiro Neto (2016), os Projetos de Lei que tentam implantar o ESP têm problemas de inconstitucionalidade por não trazerem, em suas redações, o entendimento do que seja neutralidade, política, ideologia e também daquilo que se entende por educação justa. Essas categorias carecem de respaldo técnico e jurídico e estão esvaziadas de explicações e isso pode levar a um entendimento ou a uma aplicação totalmente subjetiva das proposições.

Nenhum conhecimento é uma entidade pura, neutra, abstrata e desvinculada de contingências históricas. Entretanto, os discursos da neutralidade são recorrentemente lembrados como objetivos a serem atingidos e, de fato, suas disseminações não são uma novidade nos enunciados dos movimentos conservadores, principalmente ao se negociar as validações dos saberes. Embora não nos atenhamos aqui em descrever os processos históricos que configuram ora mais ora menos o aparecimento discursivo do neutro ou da imparcialidade, podemos apontar que o ESP, expressando uma tecnologia de poder, tenta legitimar saberes e evidências que irão compor os currículos não como disciplinas da grade escolar, mas como efeitos com constituintes de verdades discursivas; não é à toa, por exemplo, 
que as proposições do movimento rechaçam temas e discussões como desigualdade, economia, gênero e etnia e os rotulam como temas ideológicos a serem desalojados da escola. A neutralidade, neste sentido, pode ser compreendida como um anato-poder que dociliza os corpos e os categoriza ao mundo da administração, da regra, da vigília, do controle explicativo, regimental que determina aquilo que se pode ou não falar, agir ou ser (FOUCAULT, 2014).

Dentro deste plano regimental e regularizado, o ESP cria também os sujeitos ideólogos. Assim, os professores, os responsáveis por discutirem questões ideológicas nas aulas, esquecendo-se do peso do conteúdo de suas disciplinas, serão categorizados como doutrinadores e deverão ser combatidos em suas posturas críticas.

\begin{abstract}
São essas atitudes, denominadas de crítica, responsáveis por emancipar os homens, por liberá-los das formas de governo instituídas e de criarem outras capazes de promover o progresso da sociedade, ou, de não querer ser governado dessa forma - para usar uma expressão Michel Foucault - que parece ser o principal alvo dos questionamentos da Escola Sem Partido. Embora questionem mais diretamente a transmissão da doutrina e o discurso que se autodenomina crítico, supostamente desenvolvido e enunciado pelos professores, esse programa interdita precisamente essa atitude ética, por assim dizer, necessária para formação dos atores da escola, muitas vezes desenvolvidas apesar das formas de governo instituídas. Parece que os interpeladores daqueles professores denominados de críticos, ignoram que essa formação faz parte, mas extrapola o ambiente do currículo e da sala de aula, justamente porque aí temos vários estilos de conteúdo, de ensino, de vida, professados - e não um único (PAGNI; CARVALHO; GALLO, 2016).
\end{abstract}

Junto a essa interdição política e moralizante dos professores e dos conteúdos curriculares que mais se aproximam de questões sociais, o ESP (ESCOLA..., 2016) exerce uma tática de governamentalidade que cria dispositivos para flagrar o doutrinador que não se dispõe neutro e imparcial frente à sua realidade sócio-cultural. Tornam-se, portanto, fiscalizados: a) docentes que ampliam os conteúdos das disciplinas a fim de discutir cenários políticos nacionais e internacionais; b) aqueles que indicam leituras de livros de autores alinhados a correntes teóricas socialistas; c) educadores que recomendam leituras de autores que não defendem o capitalismo; d) que defendem ou alinham com a concepção de que os gêneros são categorias sociais, políticas e construídas para além do caráter biológico dado ao nascimento; e) aqueles que indicam leituras, movimentos ou manifestações que defendam direitos humanos.

$\mathrm{Na}$ construção da neutralidade e na tentativa de evidenciar as ideologias que supostamente corromperiam a escola, o ESP apoia-se numa pesquisa encomendada ao Instituto Sensus e divulgada na Revista Veja ${ }^{8}$, cuja análise sobre o papel da escola baseia-se na seguinte pergunta: "Qual você acredita que seria a missão da escola". Três opções de resposta foram dadas aos entrevistados: a) Formar cidadãos; b) Contribuir para educação profissional; e, c) Ensinar a matéria. Direcionada a educadores, a pesquisa teve como $78 \%$ das respostas que o principal objetivo da escola seria o de "Formar cidadãos". Esta posição foi veementemente criticada pelo ESP, pois segundo o movimento os professores não estão preocupados em ensinar os conteúdos de suas disciplinas, mas, sim, em realizar uma educação ideológica e partidária que se volta à transformação da sociedade. Há nesta interpretação um grande equivoco ao se confundir partido, ideologia e escola como coisas correlatas diretamente.

\begin{abstract}
A ideologia, enquanto visão de mundo, está contida em diversas esferas da vida social, inclusive escolas e partidos. Ao vincular ideologia e partido, como um par indissociável, o movimento tenta caracterizar a escola como um espaço de neutralidade, retomando conceitos de uma pedagogia tradicional, na qual o papel da escola é transmitir saber aos alunos, restando a eles assimilar os conhecimentos transmitidos. Aos alunos, reserva-se o direito de reproduzir o conhecimento, afastado de toda crítica social, política e ideológica envolvida em sua formulação e aprendizado (PAGNI; CARVALHO; GALLO, 2016).
\end{abstract}

Essa educação neutra e reprodutivista desconsidera que a LDB/1996 norteia-se pela educação cidadã, trazendo como objetivo da educação a formação para a democracia e para a vida em sociedade e que este

\footnotetext{
${ }^{8}$ Dados divulgados na Revista Veja, edição no 2074, agosto de 2008 (MATOS, 2015, p. 75-77).
} 
ideal deve ser incluído no ensino dos conteúdos, no desenvolvimento de habilidades e competências dos estudantes e na formação do senso crítico para a vida coletiva e para atuação como cidadãos.

Apesar do discurso da neutralidade, a concepção de educação empreendida pelo ESP não tem nada de inocente ou neutra. Trata-se da idéia de um currículo administrativo, organizado por blocos de conteúdos a serem transmitidos e avaliados por exames, qualificações e premiações; ela é semelhante à visão de currículo de Bobbit e Tyler defendida no início do Século XX e que, de acordo com Silva (2015), recorreria apenas à transmissão de conteúdos e informações que seriam utilizadas na vida ocupacional adulta.

Para defender a ideia de currículo administrativo e a transmissão de conteúdos, os idealizadores do ESP recorrem ao livro 'Professor não é educador', de autoria de Armindo Moreira (2013), que levanta críticas ao caráter político e autônomo da educação defendido Paulo Freire. Caberia, então, ao professor da ESP apenas o papel de instrução, pois ele não educa e nem desenvolve elo afetivo com os estudantes. Segundo o site, esta retirada do papel político da educação, levaria o docente a transmitir apenas as informações da sua matéria e a assegurar neutralidade do ensino e o combate à doutrinação.

É prudente, então, pontuar: aqueles que não se alinham a essa concepção e não se dispõem como seguidores de um padrão de ensino baseado na neutralidade política, profissional e individual estariam também simbolicamente retirados da participação nas tomadas de decisões no âmbito escolar. Por esse prisma, seria, realmente, a ESP sem partido uma escola de educação neutra?

\section{Alunos e a Participação Pública}

Com a âncora da neutralidade, o ESP assume que os alunos são receptores das informações conteudistas das disciplinas, como, também, a parte mais fraca do elo educacional, julgando-os sem condições de discernimento e posicionamentos políticos por si próprios. Os estudantes seriam, então, os aliciados e corrompidos por seu professorado, que se aproveita de suas inocências para corrompêlos em função dos valores da coletividade. As crianças e os jovens são os seres a serem tutelados para adquirirem luz, conhecimento, razão e saber sem que isso, obrigatoriamente, os contamine de orientações partidárias.

As categorias infâncias e juventude dentro do ESP, contrariando os pressupostos do Estatuto da Criança e do Adolescente (ECA), são excluídas da participação na vida pública, pois ao serem controladas por pais e tutores, desconsideram-se suas inserções sociais em termos de direitos, escolhas, consumo e vida política. Esse posicionamento também encontra raízes históricas antigas, conforme aponta Sarnento (2005) ao nos lembrar de que infância e juventude são categorias geracionais. Construídas no Ocidente como minorias, elas foram apartadas da participação na vida pública sem poder se articularem politicamente ao não deter o domínio da razão adulta. Locais como a escola e o espaço domiciliar seriam determinados a esses jovens fracos com a finalidade de, sempre sendo tutelados por alguém, serem enquadrados aos setores produtivos.

Desde a implantação da Constituição Federal de 1988, a inclusão de pautas relativas à infância e à adolescência têm se constituído num processo de múltiplos esforços. A inclusão dos direitos no ECA, os movimentos das organizações e dos Grêmios Estudantis, a participação dos estudantes na elaboração de documentos oficiais como os Regimentos Internos das Escolas e os Projetos Políticos Pedagógicos são mobilizações políticas que levam os estudantes para a cena pública.

Entretanto, dentro da discursividade do ESP o propósito é justamente outro. Trata de capturar os estudantes junto a um poder disciplinar no qual eles deixam de ser protagonistas em suas escolas e ficam distanciados das tomadas de decisão, participação democrática e pública ante as demandas escolares uma vez que as decisões caberiam somente aos pais. Assim, "a escola se torna um aparelho de aprender 
onde cada aluno, cada nível e a cada momento, se estão combinados como deve ser, são permanentemente utilizados no processo geral de ensino" (FOUCAULT, 2014, p. 163) a ser padronizado.

Ao enunciar que caberia somente à família toda $\mathrm{e}$ qualquer decisão sobre a educação dos filhos, relega-se os alunos à categoria de "tabula rasa", tratando-os como inocentes e manipuláveis, o que imputa na retirado dos mesmos da consulta e da elaboração de documentos curriculares, da participação em reivindicações por qualidade de ensino, da ocupação das instituições para a garantia de direitos e da negociação com os administradores estatais. Aliás, o ESP trata toda qualquer iniciativa de estudantes ou as lideranças dos movimentos estudantis como vinculadas a sindicatos a serviço dos partidos de esquerda ou a promotores da doutrinação política e ideológica nas escolas Este é um silenciamento que, somado à perseguição de professores, dilapida e ataca os pilares da escola democrática e os princípios constitucionais de garantia de direitos quanto à participação civil e de liberdade de expressão.

\section{A Interferência Direta da Família Parental e Esvaziamento da Escola Democrática}

Para o ESP, o currículo, as tomadas de decisões, articulações e regras dentro da escola caberiam aos pais, aos tutores ou à família. Pelo respeito aos direitos destes na educação moral de seus filhos, apregoa-se que a educação escolar também esteja adequada às convicções advindas de casa e da educação familiar. Segundo o movimento, a abordagem de questões sociais nos currículos escolares violaria esta condição, por isso há que se criar mecanismos onde os conteúdos morais sejam varridos das matérias obrigatórias e concentradas numa disciplina facultativa.

Para que este dispositivo possa ser implantado na escola, devem-se apoiar iniciativas de pais e estudantes que denunciem a doutrinação ideológica, instrumentalizá-los para que reconheçam os doutrinadores e enfrentem os problemas da melhor maneira possível; investigar a escolha pela escola de bibliografias, livros didáticos e conteúdos programáticos adequados à opinião familiar e, principalmente, promover o conhecimento sobre a doutrinação ideológica mediante a divulgação de códigos de posturas e atos normativos direcionados aos educadores.

Estas medidas do ESP afrontam diretamente o princípio da laicidade e da educação como processo democrático (MARINHO; IERVOLINO; NICOLAV, 2016). Joga-se a família contra professores e desqualifica alunos e educadores quanto às discussões políticas nos espaços educacionais. Lidas nas estrelinhas, essas mesmas medidas podem significar a privatização do espaço público escolar. De acordo com Chauí (2006, p. 131):

[...] a privatização do espaço público, sustentadas pela lógica do mercado, pelo Estado neoliberal e pela intervenção dos megaorganismos econômicos privados nas decisões dos governos, resultam na despolitização e na ideologia da competência, 'segundo a qual, os que possuem determinados conhecimentos têm o direito natural de mandar e comandar os demais em todas as esferas da existência'.

É sabido que pelos princípios democráticos, pais, mestres e corpo gestor da escola participam das tomadas de decisões e das elaborações curriculares. Ao se debruçar diretamente na proposição de interferência deste processo de gestão democrática, o ESP propõe, antes de qualquer coisa, uma educação descolada da sociedade e regida pela interferência privada em detrimento das questões que tem foro coletivo e público. As escolas públicas, sendo instituições estatais, não poderiam ser regidas por dogmas e princípios derivados de espaços privados como a família e ou a igreja. Este é o princípio que ampara a educação laica e que permite a separação do Estado da família, justamente para se evitar complicações de direito e para se preservar a coletividade e a liberdade de expressão.

$\mathrm{O}$ argumento da interferência dos pais pelo ESP é um dispositivo compulsório derivado da leitura restrita e equivocada do Artigo 12, do Pacto do Pacto de San José da Costa Rica (BRASIL, 1992), em seu $4^{\circ}$ Parágrafo, que postula que: "Os pais, e quando for 
o caso tutores, têm direito que seus filhos ou pupilos recebam a educação religiosa e moral que esteja de acordo com suas próprias convicções", especialmente para se evitar doutrinações e discussões de temas contundentes. Primeiro, isola-se o Artigo dos demais indicativos do Pacto e, em seguida, ao se amparar na interpretação deste dispositivo legal sob o baluarte de que discussões sociais afrontam a moral dos pais, criase um recorte propositalmente descolado dos demais preceitos do documento, inclusive os que garantem os direitos de liberdade de ensino e de expressão.

De acordo com Pinheiro Neto (2016), esta operação também é inconstitucional, pois se recorta uma lei de direito para se interferir na esfera de domínio público regida, juridicamente, pelos princípios liberais do Estado que garantem sim a liberdade de crença e religião pelo alunado, mas que não pode se esquivar das responsabilidades coletivas, das demandas curriculares e formativas do processo educacional do próprio Estado. Dessa forma, o movimento evoca um fragmento de legislatura de primeira instância, descontextualizado, a fim de regular o que pode ou não ser tratado na educação pública, de direito coletivo, do público, da construção democrática e da liberdade de aprender.

Apesar da incoerência legal entre as proposições do ESP e das leis de Estado, a ênfase na transmissão do conteúdo didático de forma sistemática, repetida e ainda cerceada pelas convicções familiares, interfere diretamente nos processos reflexivos e de formação dos alunos. Em termos discursivos, novamente as questões de gênero, política, raça, etnia, pertencimento cultural seriam proibidas em sala de aula, ou seja, tudo que envolve o aluno para além da aquisição de educação e informações no esteio familiar e o projeto para os espaços de socialização, convivência e contraposição de respeito, igualdade e pluralidade de ideias não poderiam ser levantadas ou debatidas. Para o movimento, caberia somente à família a formação educacional e o debate crítico e social desses temas.

É junto a este processo de distorção das competências de domínio público e privado que se instauram todas as proibições e práticas de cerceamento da liberdade docente.
Sob uma arquitetura de educação moral, implanta-se sorrateiramente uma nova inquisição cujo alvo são professores e alunos que não gostariam de compactuar com essas medidas. É sob esse preceito da regulagem, da censura, da adequação a normas com finalidades de controlar a população escolar que se constrói uma lei de mordaça e um dispositivo de punição.

\section{ADesconstrução de Educadores e Professores}

Sendo as soluções para os problemas educacionais elencados pelo ESP a neutralidade políticoideológica, o respeito à moral de pais e de tutores, o não aproveitamento da audiência cativa dos alunos, o único ator do ensinar e aprender a ser combatido é o professor. Cria-se uma representação perversa e difusa em meio a esses efeitos discursivos que o esquadrinham enquanto um novo Nosferatus ou fonte de um mal que deve ser vigiado e controlado.

A proposição de se colocar um cartaz de 90 X 70 centímetros, em cada sala de aula, expressando os conteúdos das leis e os seis deveres que devem ser seguidos à risca pelos docentes é tanto como uma lembrança do poder imperativo de uma ordem, quanto um dispositivo de vigília que, por conseqüência, também criará no espaço regimentado aquele que vigia, que sonda, que perscruta as atitudes e os conteúdos ensinados e aquele cuja função é delatar o vigiado. Isto não é apenas um cartaz ou um quadro geral de preceitos, "é um programa; ele realiza a elaboração do próprio ato, [...] uma espécie de esquema anátomo-cronológico do comportamento" (FOUCAUL, 2014, p. 149) que penetra no corpo do professor e controla minuciosamente sua ação docente. Trata-se de uma estratégia de governamentalidade e um controle panóptico que cerceia a liberdade de ensino prevista na Constituição Federal.

É Foucault (2014) quem nos lembra de que os panópticos são táticas empreendidas por uma sociedade que tem por meta disciplinar e docilizar os corpos em função daquilo que ela compreende como produtivo. A sutileza do mecanismo está justamente em normalizar pessoas, de lhes interiorizar remorsos, medos ou culpas sem que elas percebam que estão sendo alvos 
da normatização ou subordinadas a comandos de moral e de obediência. Neste sentido, o cartaz do ESP, que compulsoriamente elege e dita regras para o professor ensinar, perfaz esse poder pastoral de vigília que não se restringe a controles físicos, mas se amplia para regulações psicológicas e para sanções normalizadoras que introjetam a necessidade de constância (auto) vigilância para se perceber o desvio, aplicar-se o castigo e se garantir a punição de forma a expor a imagem do docente. Os 6 deveres do professor (ESCOLA..., 2016) demandam respeito à audiência dos alunos, o cerceamento de liberdade de expressão, a vigília sobre as manifestações eleitas como partidárias, a imposição da versão hegemônica sobre fatos históricos e sociais, a gestão particular de famílias por sobre as demandas curriculares da escola, a impossibilidade de diálogo com outros pontos de vistas extra-curriculares podem implantar um efeito de julgamento que criará "verdadeiros tribunais ideológicos e morais nas escolas, transformando o espaço escolar em um ambiente arbitrário, acusatório, completamente contraproducente ao aprendizado" (CARA, 2016, p. 45).

Sistematicamente, o site do movimento também apoia o relato de situações ou casos onde pais e estudantes se sintam ameaças ou reconheçam a ameaça doutrinária

\begin{abstract}
Assumir os supostos do Escola Sem Partido é também desconsiderar a natureza do trabalho docente e, pior, tratar os estudantes, as novas gerações e os chamados menores, como incapazes de qualquer atitude, qualquer decisão, como se fossem uma geração sem coragem [...]. Dessa forma, a implementação desse programa concorre para a destruição de uma das principais virtudes da educação escolar moderna, talvez, porque jamais seus apoiadores tenham abandonado, mesmo se um dia foram professores e estiveram na sala de aula para o exercício do magistério, a prática do pastoreio ou, quem sabe, desejem que toda a nova geração sejam boas ovelhas para um amplo rebanho, como foram e são no mundo atual, sem pensar que esse ideal já se demonstrou falho, obtuso, equivocado, autoritário para si mesmo e, quiçá, para os outros (PAGNI; CARVALHO; GALLO, 2016).
\end{abstract}

A lei não precisa estar aprovada e sancionada, o que rege são os efeitos destas, que já tem reverberado nos espaços de ensino. Pune-se a atuação docente com um mecanismo de descaracterização e exibição de sua prática tal qual se fazia nos períodos inquisitoriais (FOUCAULT, 2014).

Vale salientar que o Ministério Público Federal se manifestou contrário ao ESP, abrindo precedentes para posicionamentos junto à Procuradoria Federal dos Direitos do Cidadão através da Nota Técnica 001/2016. Este documento demarca os Projetos de Lei derivados do ESP como inconstitucionais, especialmente no que tange a: a) vigilância dos professores; b) confusão da educação escolar com a educação privada fornecida pelos pais; c) impedimento do pluralismo de ideias e concepções pedagógicas; d) negação do princípio de cátedra e da possibilidade de ampla aprendizagem; e, e) desrespeito ao princípio da laicidade do Estado, que determina que os valores particulares/morais não podem a interferir nos espaços de ensino (BRASIL, 2016).

Mais recentemente, o Procurador Geral da República, Rodrigo Janot, em 19 de outubro de 2016, emitiu parecer favorável a inconstitucionalidade do Projeto de Lei Alagoano 'Escola Livre', derivado do movimento ESP, alegando que o mesmo cerceia a liberdade de ensino e de expressão, usurpa as competências do âmbito privado para educação pública e subestima o alunado em suas capacidades críticas e cognitivas.

Diversos professores da educação básica e do ensino superior também se organizam em redes e debates sociais posicionando-se contrários à implantação do ESP. O movimento Professores contra o Escola sem Partido9 articula a divulgação de argumentos sociológicos, científicos e educacionais amparados em diversas teorizações respeitadas nos âmbitos jurídicos e social. Diversas associações como a Associação Nacional de Pesquisa em Educação (ANPED) e a Sociedade Nacional para o Ensino de Biologia (SBENBIO), mais algumas universidades públicas e pesquisadores renomados emitiram notas de repúdio e coordenam abaixo-assinados enviados à Câmara e ao Senado para impedir que o ESP seja votado e se torne Lei.

\footnotetext{
${ }^{9}$ Disponível em: <https://www.facebook.com/contraoescolasempartido>. Acesso em 10 de outubro de 2016
} 


\section{Voltaremos a Dayton? Algumas Considerações} a Pensar

Muitos movimentos sociais, com parcerias junto ao Estado ou não, atuam pleiteando modificações nos currículos algumas vezes para incluir e dialogar com as diferenças, noutras para se adequar às proposições internacionais e aos tratados do qual o país é signatário, e também como mobilizações para silenciar certos grupos sociais e negar suas participações nos espaços de ensino. Nos últimos vinte anos, avanços em torno das questões de diversidade, desigualdades, identidades e diferenças têm ganhado espaço nas discussões curriculares e nas políticas públicas educacionais, contudo, à medida que as novas identidades ganham espaço, manobras conservadoras tentam impedir que elas ocupem a cena pública e, para tanto, buscam em territórios de forças e em relações de poder e saber operar em documentos oficiais. Táticas coercitivas e proibitivas criam uma vigilância hierarquizada que amplia as políticas de proibição nas escolas.

Em meio a essas polarizações contraditórias em termos de objetivos e investimentos em educação e formação, o ESP tem avançado consideravelmente no Brasil, Alegando a necessidade de neutralidade na educação, o movimento corrobora para retirar os estudantes dos processos democráticos de produção de saberes e da vida pública escolar. Perscruta temas de relevância social como a inserção das diferenças étnicas, de gênero, de classe transversalizadas nos conteúdos das disciplinas e vividas junto aos debates do ensinar e aprender.

Ao se permitir a inversão hierárquica dos princípios da laicidade, infere também na gestão democrática escolar e minimiza a coletividade em função da moralidade de pais e família. Enviesa a leitura dos princípios da sociologia e do marxismo e reportam o educador como a um mal a ser combatido para se evitar doutrinações específicas e perigosas à ordem econômica e social vigente.

Como no episódio do início do século em Tennesse e traçando um paralelismo entre os dois contextos de época, o ESP se modula através de discursos e práticas coercitivas, de vigília, controle e de delação cujos alvos são docentes que, supostamente, se contrapõem aos ordenamentos morais da família, à educação dada pelos pais. Cria maniqueísmos e relações de diferença ao categorizar o bom e o mau professor e ao ordenar um sujeito perturbador da ordem e corruptor de estudante, tomando como ponto de partida as opiniões contrárias ao regime econômico capitalista e alinhadas a posicionamentos de fóruns sociais e pluralistas.

É uma pedagogia cultural que atua disseminando biopoderes e biopolíticas para controlar os corpos e as práticas escolares. Embora se paute na tese de que educar é instruir, sem fazer distinção entre esses dois princípios, traz uma visão de currículo meramente administrativo e técnico que imprimirá, como efeito dos discursos que também apregoa uma educação competitiva, acrítica e desconectada da sociedade. Fomenta a (auto)vigilância, a deleção e a punição expositiva e adultera o potencial político da educação dos atores escolares.

Apesar dos professores que denunciam as incoerências e a inconstitucionalidade do ESP, enfatizando a importância do diálogo com a diversidade, os movimentos sociais, a sociedade civil, os profissionais de ensino e as instituições de pesquisa acadêmica, o movimento dissemina-se numa rede complexas onde artefatos e pedagogias como sites, livros, cartilhas, folders, cartazes, vídeos, entrevistas e canais em redes sociais como o Facebook e o Youtube, conseguindo seguidores e penetrando nas escolas. Contam, também, com o apoio de entidades conservadoras e setores religiosos que pretendem incidir nas escolhas educacionais e nas proposições curriculares.

Não gostaríamos de um retorno a Dayton e nem que nossas liberdades de ensinar e práticas docentes estejam circunstanciadas a vigílias temerosas e a padronizações que tomam o exercício docente como crime e castigo. Para que haja pluralidade de vozes na construção de currículos e na formação de consciências cidadãs, enfatizamos o exercício de um pensamento contextualizado e atento às entrelinhas do ESP e pedimos que não se criminalizem a pluralidade de saberes. Que permaneça a escola dentro dos princípios democráticos e dentro dos ideais de liberdade. 


\section{Referências}

APPLE, M. Educação e poder. Porto Alegre: Artes Médicas, 1989.

ARROYO, M. G. Os movimentos sociais e a construção de outros currículos. Educar em Revista, Curitiba, v. 55, p. 47-68, 2015.

BRASIL. Decreto $n^{\circ} 678$, de 6 de novembro de 1992. Promulga a Convenção Americana de Direitos Humanos (Pacto de São José da Costa Rica), de 22 de novembro de 1969). Disponível em: <http:// www.planalto.gov.br/ccivil_03/decreto/d0678.htm>. Acesso em: 15 set. 2016.

. Lei 9.394 de 20 de dezembro de 1996. Estabelece diretrizes e bases da educação nacional. Disponível em: <https://www.planalto.gov.br/ ccivil_03/Leis/L9394.htm>. Acesso em: 15 set. 2016.

- Ministério Público Federal. Procuradoria

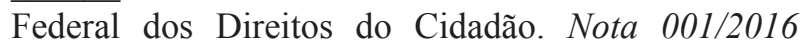
$P D D C$. Quanto à inconstitucionalidade do Escola Sem Partido. 2016. Disponível em: <http://pfdc.pgr. mpf.mp.br/temas-de-atuacao/educacao/saiba-mais/ proposicoes-legislativas/nota-tecnica-01-2016-pfdcmpf $>$. Acesso em: 10 out. 2016.

Projeto de lei da Câmara Federal 867/2015. "Programa Escola sem Partido". Disponível em: $<$ http://www.camara.gov.br/sileg/integras/1317168. pdf $>$. Acesso em: 11 set. 2016.

. Projeto de Lei do Senado 193/2016. Inclui entre as diretrizes e bases da educação nacional, de que trata a Lei $n^{\circ}$ 9.394, de 20 de dezembro de 1996, o "Programa Escola sem Partido". 2016c.Disponível em: $\quad<$ https://www12.senado.leg.br/ecidadania/ visualizacaomateria?id=125666>. Acesso em: 11 set. 2016.

CALADO, J. Os limites da ciência. Lisboa: Fundação Francisco Manuel dos Santos, 2014.

CARA, D. O Programa "Escola Sem Partido" quer uma escola sem educação. In: SOUZA, A L. S et al. A ideologia do movimento escola sem partido: 20 autores desmontam o discurso. São Paulo: Ação Educativa, 2016. p. 23-48.
CARVAlho, F. A. et al. Políticas públicas e (in) visibilidades escolares: entre (des)conhecer, apagar e trabalhar com o combate à violência de gênero. In: CORREA, C. M. A.; MAIO, E. R. Observatório de violência de gênero: entre políticas públicas e práticas pedagógicas. Curitiba: CRV, 2015. p. 99-115.

CHAUÍ, M. Fundamentalismo religioso: a questão do poder teológico-político. In: BORON, A. A. Filosofia política contemporãnea: controvérsias sobre civilização, império e cidadania. Buenos Aires: Consejo Latinoamericano de Ciencias Sociales CLACSO, 2006. p. 115-129.

CHAUÍ, M. Manifestações ideológicas do autoritarismo brasileiro. Belo Horizonte: Autêntica, 2014.

ESCOLA sem partido. Disponível em: <http://www. escolasempartido.org>. Acesso em: 20 nov. 2016.

FOUCAULT, M. A história da sexualidade I: a vontade de saber. Rio de Janeiro: Graal, 1988.

- A história da sexualidade II: o uso dos prazeres. Rio de Janeiro: Graal, 1984.

- Arqueologia do saber. Rio de Janeiro: Forense-Universitária, 1987.

- Tecnologias del yo y otros textos afines. Barcelona: Ediciones Paidós Ibérica S/A, 1995.

. Vigiar e punir: nascimento da prisão. 42. ed. Petrópolis-RJ: Vozes, 2014.

GIROUX, H. Atos impuros: a prática política dos estudos culturais. Porto Alegre: Artes Médicas, 2003.

. Os professores como intelectuais: rumo a uma nova pedagogia crítica da aprendizagem. Porto Alegre: Artes Médicas, 1997.

GOODSON, I. F. Currículo: teoria e história. 8. ed. Petrópolis-RJ: Vozes, 2008.

LIONÇO, T. Fundamentalismo religioso e estado laico: reunião ampliada 12 e 13 de outubro de 2013. 2015. Disponível em: <https:/https://br.boell.org/sites/default/ files/fundamentalismo_religioso_e_estado_laico_-_reuniao_ ampliada.pdf $>$. Acesso em: 10 jan. 2016. 
MARINHO, J.; IERVOLINO, T.; NICOLAV, V. Sem partido e sem educação? Conheça os projetos de lei que questionam a formação cidadã na sala de aula. 30 jun. 2016. Disponível em: $<$ https://educacaoeparticipacao. org.br/acontece/sem-partido-e-sem-educacao/>. Acesso em: 5 out. 2016.

MATOS, B. T. P. Doutrinação política e ideológica na escola. Brasília, 24 mar. 2015. Disponível em: <http:// www2.camara.leg.br/atividade-legislativa/comissoes/ comissoes-permanentes/ce/audiencias-publicas-1/ apresentacoes/apresentacao-braulio-matos>. Acesso em: 10 out. 2016.

MOREIRA, A. Professor não é educador. 3. ed. Brasília: Editora Edesio, 2013.

PAGNI, P.; CARVALHO, A. F.; GALlO, S. $O$ programa Escola Sem Partido e a destruição de uma das virtudes modernas da escola. Disponível em: $<$ http://www.anped.org.br/news/o-programa-escolasem-partido-e-destruicao-de-uma-das-virtudesmodernas-da-escola>. Acesso em: 10 out. 2016.

PINHEIRO NETO, O. As múltiplas inconstitucionalidades e equívocos dos projetos de lei "Escola sem Partido". Revista Jus Navigandi, Teresina, ano 21, n. 4595, 30 jan. 2016. Disponível em: <https://jus.com.br/artigos/46182/as-multiplasinconstitucionalidades-e-equivocos-dos-projetos-delei-escola-sem-partido>. Acesso em: 10 out. 2016.

POLIZEL, A. L.; CARVALHO, F. A. Um currículo que violenta: invisibilidades e reações pós apagamentos. In: CONGRESSO INTERNACIONAL DO NÚCLEO DE ESTUDOS DE GÊNERO E DIREITO (NEG) E DO NÚCLEO DE POLÍTICA CRIMINAL (NUPOC) - UMA DÉCADA DE LEI MARIA DA PENHA: PERCURSOS, PRÁTICAS E DESAFIOS, 1., 2016, Maringá. Anais... Maringá: Universidade Estadual de Maringá, 2016. p. 88-92. Disponível em: <http:// media.wix.com/ugd/c31adb_809608c6367e4aae89bd 0484f4eb1967.pdf>. Acesso em: 10 out. 2016.

RATIER, R. 14 perguntas e respostas sobre o "Escola sem Partido". In: SOUZA, A L. S et al. A ideologia do movimento escola sem partido: 20 autores desmontam o discurso. São Paulo: Ação Educativa, 2016. p. 29-42.

REVEL, J. Michel Foucault: conceitos essenciais. São Carlos: Claraluz, 2005.
RIO DE JANEIRO (Estado). Projeto de Lei $n^{o}$ 2.974/2014. Cria, no âmbito do sistema de ensino do Estado do Rio de Janeiro, o "Programa Escola sem Partido". Disponível em: <http://alerjln1.alerj.rj.gov. br/scpro1115.nsf/e4bb858a5b3d42e383256cee006ab6 6a/45741a7e2ccdc50a83257c980062a2c2?OpenDocu ment>. Acesso em: 5 out. 2016.

RODRIGUES, T. C.; ABRAMOWICZ, A. O debate contemporâneo sobre identidade e diferença nas políticas educacionais e estudos. Educação e Pesquisa, São Paulo, v. 39, n. 1, p. 15-30, 2013.

SANTOMÉ, J. T. As culturas negadas e silenciadas no currículo. In: SILVA, T. T. (Org.). Alienígenas na sala de aula: uma introdução aos estudos culturais em educação. Petrópolis: Vozes, 2013. p. 159-177.

SARNENTO, M. J. Geração e alteridade: interrogações a partir da sociologia da infância. Educação \& Sociedade, Campinas, v. 26, n. 9, p. 361-378, 2005.

SILVA, A. B. et al. A extrema-direita na atualidade. Revista Serviço Social \& Sociedade, São Paulo, n. 119, p. 407-445, jul./set. 2014.

SILVA, T. T. Documentos de identidade: uma introdução às teorias do currículo. 3. ed. Belo Horizonte: Autêntica, 2015.

. Identidades terminais: as transformações na política da pedagogia e na pedagogia da política. Petrópolis: Vozes, 1996.

XIMENES, S. O que o direito à educação tem a dizer sobre "Escola Sem Partido"? In: SOUZA, A L. S et al. A ideologia do movimento escola sem partido: 20 autores desmontam o discurso. São Paulo: Ação Educativa, 2016. p. 49-58. 